\title{
A convenient method to assess air infiltration rate using particle mass balance principle
}

\author{
Yuchen $\mathrm{Shi}^{1}$ and Xiaofeng $\mathrm{Li}^{1, *}$ \\ ${ }^{1}$ Tsinghua University, Beijing, 100084, China
}

\begin{abstract}
Uncontrolled air leakage across a building exterior (i.e., air infiltration) is a primary reason for excessive energy consumption of air conditioning systems and indoor particle pollution, because infiltration brings outdoor high dew point air and particulate pollutants indoors. Therefore, assessing air infiltration rate is very necessary for improving building energy performance and indoor air quality. However, the commonly used method to assess infiltration rate is very complex to implement. In this paper, we propose a convenient method to assess the infiltration rate based on the mass balance of particulate matters. Given the ubiquity of particulate matters in the outdoor environment and being cost-free, this method is able to avoid the disadvantages of traditional methods. PM2.5 is chosen to establish the mass balance. The method was used in an office room to measure the infiltration rate. Simultaneously, the carbon dioxide tracer gas method was used to verify our method. The relative error between the results calculated by our method and the verifying method is within $10 \%$, which indicates that the proposed method would be feasible in practical applications.
\end{abstract}

\section{Introduction}

Air infiltration, which means the uncontrolled air leakage across a building envelop, is a primary reason for the excessive energy consumption of air conditioning systems [1]. Researchers have found that improving the airtightness of building envelopes would save building energy consumption by 3 to $36 \%$ in America [2]. In the cold regions of China, when the infiltration rate was reduced from 0.3 to $0.03 \mathrm{ACH}$, the annual heating and cooling load in a public building was reduced by more than $40 \%$ [3]. Besides, air infiltration brings outdoor particulate matters indoors and directly influences indoor air quality, especially when the outdoor air is highly polluted. Studies have concluded that indoor PM2.5 concentrations are highly correlated with outdoor concentration levels because of air infiltration [4, 5]. Therefore, determining air infiltration rate is very necessary for improving building energy performance and indoor air quality.

The most commonly used method to measure the infiltration rate is the tracer gas method [6]. The tracer gas method uses tracer gas dilution for calculating a single zone's air change rate with the outdoors. There are three kinds of techniques used in the tracer gas method: concentration decay, constant injection, and constant concentration. Among them concentration decay is the most widely used one, which has been used in office buildings [7], residential buildings [8], classrooms [9], and retail stores [10]. The test procedure of tracer gas method consists of the release, mixture, and monitor of suitable tracer gas (such as carbon dioxide, $\mathrm{CO}_{2}[11]$ and sulphur hexafluoride, $\mathrm{SF}_{6}$ [12]). The method is very complex to implement and takes several hours to get one result [6]. Besides, the cost of tracer gas is relatively high, especially if the space volume is large. Due to these difficulties, numerous researches have used an assumed constant infiltration rate in their calculations and simulations $[13,14]$. Hence, a simpler method is urgently needed for assessing infiltration rate.

During the past decade, the haze pollution in China is very serious [15]. The main component of haze is fine particulate matters, which are particles with a maximum diameter of $2.5 \mu \mathrm{m}$ (abbreviated as PM2.5) and can be inhaled into the lungs [16]. As mentioned before, particles will infiltrate indoors. In order to keep a low indoor PM2.5 concentration, air purifiers are extensively used in the indoor environment in China [17]. Besides, due to people's sustained attention to PM2.5, the measuring instruments and on-line monitoring of PM2.5 are prevalent and of mature technology.

In this paper, we propose a convenient method to assess the air infiltration rate based on the mass balance of particulate matters. Given the ubiquity of particulate matters in the outdoor environment and being cost-free, this method is able to avoid the disadvantages of the tracer gas method. PM2.5 is chosen to establish the mass balance. Air infiltration rates of an office room with air purifiers were measured using the PM2.5 mass balance and carbon dioxide tracer gas decay methods at the same time. The results of tracer gas decay method are used to verify those of our proposed method. Besides, considering that PM2.5 deposits indoors [18], sensitivity analysis is conducted for PM2.5 deposition rate.

\footnotetext{
* Corresponding author: xfli@tsinghua.edu.cn
} 


\section{Method}

\subsection{PM2.5 mass balance}

Taking the internal room space as the control body, the PM2.5 mass balance is shown in Fig.1. PM2.5 gets indoors along with air infiltration. PM2.5 concentration of infiltration airflow is affected by outdoor particle level and the penetration factor. After getting indoors, part of the particles deposits on indoor surfaces, and part of them is filtered by the air purifier. If outdoor PM2.5 concentration is constant for a given time period, the indoor PM2.5 concentration will eventually come to a steady state. The steady-state PM2.5 mass balance equation is expressed as

$$
P Q_{\text {inf }} c_{\text {out }}=Q_{\text {inf }} c_{\text {in }}+Q_{p} \eta_{p} c_{\text {in }}+K V c_{\text {in }}
$$

where $P$ is penetration factor, dimensionless; $Q_{\text {inf }}$ is infiltration rate, $\mathrm{m}^{3} / \mathrm{h} ; c_{\text {out }}$ is outdoor PM2.5 concentration, $\mu \mathrm{g} / \mathrm{m}^{3} ; c_{i n}$ is indoor PM2.5 concentration, $\mu \mathrm{g} / \mathrm{m}^{3} ; Q_{p}$ is the air supply rate of air purifier, $\mathrm{m}^{3} / \mathrm{h} ; \eta_{p}$ is the filtration efficiency of air purifier, dimensionless; $K$ is PM2.5 deposition rate, $\mathrm{h}^{-1} ; V$ is room volume, $\mathrm{m}^{3}$.

The Clean Air Delivery Rate, which is an important parameter of an air purifier, is defined as the product of air supply rate and filtration efficiency as follows [19]:

$$
C A D R=Q_{p} \eta_{p}
$$

The I/O ratio of PM2.5 for the steady state is given by Eq. (3) [20]:

$$
I / O_{\text {ratio }}=\frac{c_{\text {in }}}{c_{\text {out }}}
$$

Substituting Eqs. (2) and (3) into Eq. (1), the air infiltration rate is calculate by the following equation:

$$
Q_{\text {inf }}=\frac{I / O_{\text {ratio }}(C A D R+K V)}{P-I / O_{\text {ratio }}}
$$

According to Eq. (4), when $\mathrm{I} / \mathrm{O}$ ratio, CADR, room volume, deposition rate, and penetration factor are determined, the infiltration rate can be calculated. Among them, the I/O ratio, CADR, and room volume are obtained by measurement. Penetration factor indicates that some particles may deposit on the cracks of windows or doors. It is the ratio between particle concentration after penetrating and outdoor particle concentration. The larger the particle size, the smaller the penetration factor is. Numerous studies have demonstrated that PM2.5 penetration factor is very close to 1 and usually set to 1 $[18,21,22]$. Researchers have found that the indoor deposition rate is $0.39 \pm 0.16 \mathrm{~h}^{-1}$ for PM2.5 [21]. In this study, the PM2.5 deposition rate is set to $0.39 \mathrm{~h}^{-1}$. Then, sensitivity analysis is conducted for the deposition rate within the range of $0.23-0.55 \mathrm{~h}^{-1}$.

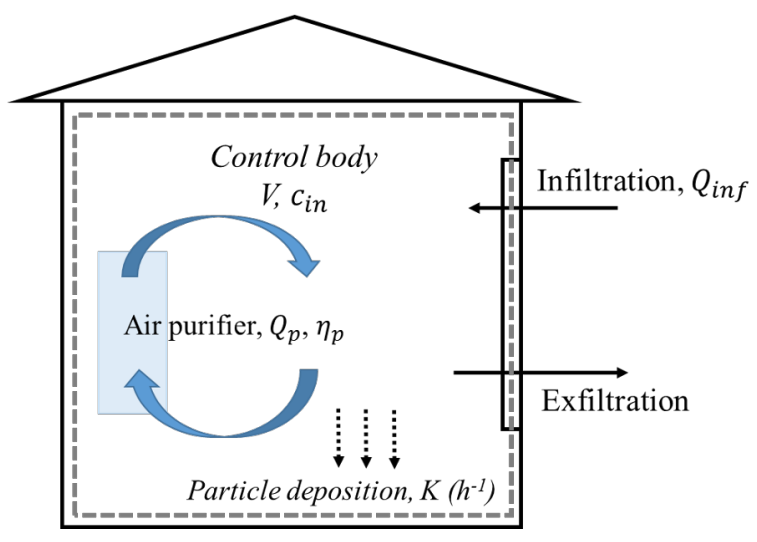

Fig. 1. Indoor PM2.5 mass balance.

\subsection{Measuring procedures}

Air infiltration rate measurements are conducted by the following steps:

a) Measure the room volume $V$;

b) Measure the air supply rate $Q_{p}$ and filtration efficiency $\eta_{p}$ of indoor air purifiers (or refer to the product specification of air purifiers to determine the CADR);

c) Set up indoor and outdoor PM2.5 concentration monitors;

d) Turn on indoor air purifiers;

e) Monitor indoor and outdoor PM2.5 concentrations until indoor PM2.5 concentration stops declining and becomes stable, then the $\mathrm{I} / \mathrm{O}$ ratio for the steady state is determined by Eq. (3).

f) Calculate the infiltration rate using Eq. (4).

\subsection{Validation}

In order to verify our proposed method, tracer gas decay method is simultaneously used to measure the infiltration rate. Carbon dioxide $\left(\mathrm{CO}_{2}\right)$ is chosen as the tracer gas because it is easily available. In the $\mathrm{CO}_{2}$ decay method, $\mathrm{CO}_{2}$ is injected into the test room and the decay of $\mathrm{CO}_{2}$ concentration is measured once a uniform concentration has been reached. The change of indoor $\mathrm{CO}_{2}$ concentration is expressed as

$$
\ln \left[C_{\text {in }}(\tau)-C_{\text {out }}(\tau)\right]=-N \tau+\ln \left[C_{\text {in }}(0)-C_{\text {out }}(0)\right]
$$

where $C_{\text {in }}$ and $C_{\text {out }}$ are indoor and outdoor $\mathrm{CO}_{2}$ concentrations, ppm; $N$ is air change rate, $\mathrm{h}^{-1}$; and $\tau$ is time, h. Based on Eq. (5), $N$ can be determined through the linear fitting between $\ln \left[C_{\text {in }}(\tau)-C_{\text {out }}(\tau)\right]$ and $\tau$.

Then, the infiltration rate of the test room is calculated using Eq. (6):

$$
Q_{\text {inf }}=N \times V
$$


The $\mathrm{CO}_{2}$ decay method is conducted by the following procedures:

a) Measure the room volume $V$;

b) Set up indoor and outdoor $\mathrm{CO}_{2}$ concentration monitors;

c) Release $\mathrm{CO}_{2}$ to the test room until indoor $\mathrm{CO}_{2}$ concentration is much higher than the outdoor concentration ;

d) Turn on electric fan to mix the air till indoor $\mathrm{CO}_{2}$ concentration is uniform;

e) Leave the room and monitor the decay of $\mathrm{CO}_{2}$ concentration;

f) Calculate the air change rate $N$ using Eq. (5) and the infiltration rate using Eq. (6).

\section{Results}

The test room is situated on the $35^{\text {th }}$ floor of an office building. The floor area is measured to be $270.3 \mathrm{~m}^{2}$ and its volume is $867.8 \mathrm{~m}^{3}$. Fig. 2 illustrates the layout of the test room. It has an eastern interior door open to the hallway, and northern and southern exterior windows. There are six measuring points indoors for PM2.5 and $\mathrm{CO}_{2}$ concentrations and two outdoors. The height of indoor measuring points is half the room height $(1.6 \mathrm{~m})$. The instruments used in the tests are listed in Table 1.

Tests were conducted on April 22 and 23, 2017. There are three ceiling mounted air purifiers in the test room. The air supply rates and filtration efficiencies of these air purifiers are listed in Table 2. The total CADR of these air purifiers is $1687 \mathrm{~m}^{3} / \mathrm{h}$.

The test results on April 22, 2017 are shown in Figs. 3 and 4. As illustrated in Fig. 3, the outdoor PM2.5 concentration is stable during the test period. That is because the horizontal static wind is one of the main reasons for the formation of hazy weather and can cause a steady outdoor concentration of PM2.5 for a period of time [23], which also validates our assumption for Eq. (1). The indoor PM2.5 concentration declines and reaches a stable value after turning on the air purifiers for 1 hour. The steady-state PM2.5 I/O ratio is 0.23 and the infiltration rate calculated by PM2.5 mass balance method is $606 \mathrm{~m}^{3} / \mathrm{h}$. The $\mathrm{CO}_{2}$ decay method was conducted at the same time with the PM2.5 mass balance method. The decay of $\mathrm{CO}_{2}$ concentration is shown in Fig. 4. The air change rate is $0.7236 \mathrm{~h}^{-1}$ and the infiltration rate calculated by $\mathrm{CO}_{2}$ decay method is $645 \mathrm{~m}^{3} / \mathrm{h}$. Hence, the relative error between the two methods is $6.0 \%$.

Duplicate test was conducted on April 23, 2017. The test results of April 22 and 23, 2017 are listed in Table 3. The relative errors between the results calculated by the PM2.5 mass balance and $\mathrm{CO}_{2}$ decay methods are within $10 \%$, which proves that our proposed method is feasible in practical applications.

Sensitivity analysis is conducted for the PM2.5 deposition rate within the range of $0.23-0.55 \mathrm{~h}^{-1}$. Results are shown in Table 4 . The relative errors between the results calculated by the PM2.5 mass balance and $\mathrm{CO}_{2}$ decay methods are no more than $15 \%$ when deposition rate varies, which indicates that the infiltration rate is not sensitive to the deposition rate and our proposed method is reliable for assessing infiltration rates.

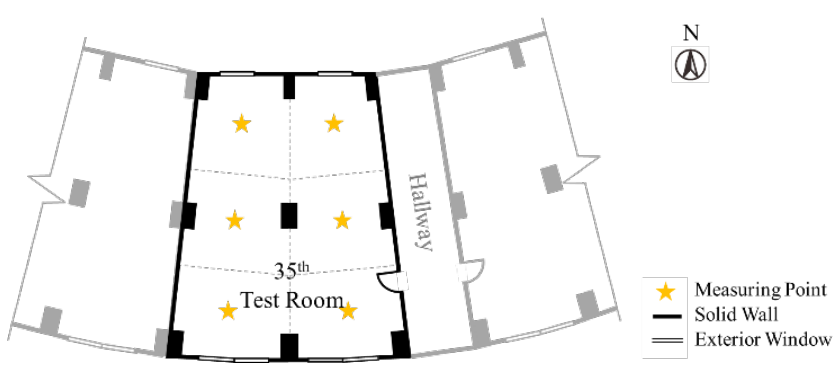

Fig. 2. Floor plan of the test room.

Table 1. Instrument list.

\begin{tabular}{|l|l|l|l|}
\hline Instrument & Model & Accuracy & Usage \\
\hline Tape measure & $\begin{array}{l}\text { Tajima } \\
\text { Hilock-25 }\end{array}$ & $\pm 0.5 \mathrm{~mm}$ & $\begin{array}{l}\text { Measuring } \\
\text { room volume } \\
\text { and air supply } \\
\text { rate of air } \\
\text { purifiers }\end{array}$ \\
\hline $\begin{array}{l}\text { Hot wire } \\
\text { anemometer }\end{array}$ & TSI 962 & $\begin{array}{l} \pm 0.015 \mathrm{~m} / \mathrm{s} \\
\text { or } \\
\pm 3 \% \text { of } \\
\text { reading }\end{array}$ & $\begin{array}{l}\text { Measuring air } \\
\text { supply rate of } \\
\text { air purifiers }\end{array}$ \\
\hline $\begin{array}{l}\text { PM2.5 } \\
\text { concentration } \\
\text { monitor }\end{array}$ & TSI AM510 & $/$ & $\begin{array}{l}\text { Measuring } \\
\text { indoor and } \\
\text { outdoor } \\
\text { PM2.5 } \\
\text { concentrations }\end{array}$ \\
\hline $\begin{array}{l}\text { CO } 2 \\
\text { concentration } \\
\text { monitor }\end{array}$ & Telaire 7001 & $\begin{array}{l} \pm 50 \text { ppm or } \\
\pm 5 \% \text { of } \\
\text { reading }\end{array}$ & $\begin{array}{l}\text { Measuring } \\
\text { indoor and } \\
\text { outdoor } \mathrm{CO}_{2} \\
\text { concentrations }\end{array}$ \\
\hline
\end{tabular}

Table 2. Clean air delivery rate.

\begin{tabular}{|c|c|c|c|}
\hline & $Q_{p}\left(\mathrm{~m}^{3} / \mathrm{h}\right)$ & $\eta_{p}$ & $C A D R\left(\mathrm{~m}^{3} / \mathrm{h}\right)$ \\
\hline Air purifier 1 & 665 & $78 \%$ & 518 \\
\hline Air purifier 2 & 657 & $77 \%$ & 503 \\
\hline Air purifier 3 & 848 & $79 \%$ & 666 \\
\hline Total CADR $\left(\mathrm{m}^{3} / \mathrm{h}\right)$ & \multicolumn{3}{|c|}{1687} \\
\hline
\end{tabular}



Fig. 3. PM2.5 concentration on April 22, 2017. 


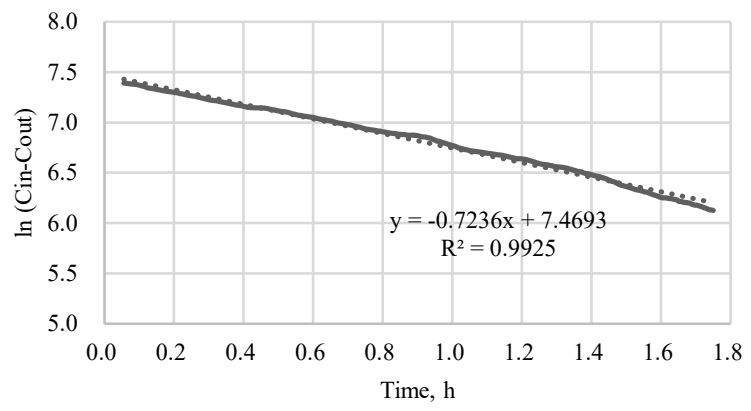

Fig. 4. $\mathrm{CO}_{2}$ decay on April 22, 2017.

Table 3. Test results.

\begin{tabular}{|c|c|c|}
\hline & Test 1 & Test 2 \\
\hline Date & $2017 / 4 / 22$ & $2017 / 4 / 23$ \\
\hline $\begin{array}{c}\text { Outdoor PM2.5 concentration } \\
\left(\mu \mathrm{g} / \mathrm{m}^{3}\right)\end{array}$ & 45 & 93 \\
\hline $\begin{array}{c}\text { Indoor steady-state PM2.5 } \\
\text { concentration }\left(\mu \mathrm{g} / \mathrm{m}^{3}\right)\end{array}$ & 10 & 15 \\
\hline $\mathrm{I} / \mathrm{O}$ ratio & 0.23 & 0.16 \\
\hline $\begin{array}{c}\text { Infiltration rate by } \mathrm{PM} 2.5 \text { mass } \\
\text { balance method }\left(\mathrm{m}^{3} / \mathrm{h}\right)\end{array}$ & 606 & 384 \\
\hline $\begin{array}{c}\text { Air change rate by } \mathrm{CO}_{2} \text { decay } \\
\text { method }\left(\mathrm{h}^{-1}\right)\end{array}$ & 0.7236 & 0.4168 \\
\hline $\begin{array}{c}\text { Infiltration rate by } \mathrm{CO}_{2} \text { decay } \\
\text { method }\left(\mathrm{m}^{3} / \mathrm{h}\right)\end{array}$ & 645 & 371 \\
\hline $\begin{array}{c}\text { Relative error between two } \\
\text { methods }\end{array}$ & $6.0 \%$ & $3.5 \%$ \\
\hline
\end{tabular}

Table 4. Sensitive analysis for deposition rate.

\begin{tabular}{|c|c|c|}
\hline & Test 1 & Test 2 \\
\hline Date & $2017 / 4 / 22$ & $2017 / 4 / 23$ \\
\hline $\begin{array}{c}\text { Input parameter } \\
\text { Set value of the input } \\
\text { parameter }\end{array}$ & PM2.5 deposition rate, $K\left(\mathrm{~h}^{-1}\right)$ \\
\hline $\begin{array}{c}\text { Range of the input } \\
\text { parameter }\end{array}$ & \multicolumn{2}{|c|}{$0.39 \mathrm{~h}^{-1}$} \\
\hline $\begin{array}{c}\text { Infiltration rate } \\
\text { calculated by PM2.5 } \\
\text { mass balance method } \\
\left.\text { (m } \mathrm{m}^{3} / \mathrm{h}\right)\end{array}$ & $564-649$ & $357-411$ \\
\hline $\begin{array}{c}\text { Relative error to the } \\
\text { infiltration rate } \\
\text { calculated by CO } \\
\text { decay method }\end{array}$ & $-12.6-0.6 \%$ & $-10.7-3.8 \%$ \\
\hline
\end{tabular}

\section{Discussion}

This method provides a convenient way to assess the infiltration rate that is generally considered difficult to measure. The method is based on the particle mass balance principle. In practical uses, the infiltration rate can be easily assessed using an air purifier and several PM2.5 sensors. The method can also be used in rooms ventilated by air handling units (AHUs), because AHUs have filters and the return air rate acts as $Q_{p}$.

Especially, due to the outdoor PM2.5 pollution, air purifiers with PM2.5 sensors are widely used indoors in China. Besides, the real-time outdoor PM2.5 concentration is issued every hour by government websites. The above facts make it very convenient to assess infiltration rates using our proposed method.

\section{Conclusion}

The assessment of air infiltration rate is very necessary for improving building energy performance and indoor air quality. However, the commonly used method is complex to implement. This paper proposes a convenient method to assess air infiltration rate based on the particle mass balance principle. The method was used to measure infiltration rates for an office room. In order to verify our proposed method, the tracer gas decay method was used simultaneously. Then, sensitivity analysis was conducted for the particle deposition rate. The relative error between the results calculated by our method and the verifying method is within $10 \%$. And the relative error is lower than $15 \%$ when the particle deposition rate changes within its range. These results prove that our proposed method is reliable for assessing infiltration rates and feasible in practical applications.

\section{References}

[1] F. d. A. Alfano, M. Dell'Isola, G. Ficco, and F. Tassini, "Experimental analysis of air tightness in Mediterranean buildings using the fan pressurization method," Building and environment, vol. 53, pp. 16-25, 2012.

[2] S. J. Emmerich, T. P. McDowell, and W. Anis, Investigation of the impact of commercial building envelope airtightness on HVAC energy use. US Department of Commerce, Technology Administration, National Institute of Standards and Technology, 2005.

[3] J. Lin, "Application Strategy Research of Natural Ventilation in the Three Types of Climatic Conditions in Shaanxi Province," Master Thesis, Xi'an University of Architecture and Technology, China, 2011.

[4] Q. Y. Meng et al., "How does infiltration behavior modify the composition of ambient PM2. 5 in indoor spaces? An analysis of RIOPA data," Environmental science \& technology, vol. 41, no. 21, pp. 7315-7321, 2007.

[5] C. Chen and B. Zhao, "Review of relationship between indoor and outdoor particles: I/O ratio, infiltration factor and penetration factor," Atmospheric Environment, vol. 45, no. 2, pp. 275-288, 2011.

[6] Standard Test Method for Determining Air Change in a Single Zone by Means of a Tracer Gas Dilution, ASTM Standard E741, American Society of Testing and Materials, Philadelphia, 2010. 
[7] J. T. Reardon, M. R. Atif, and S. Chia-yu, "Tracer gas measurements for ventilation, air movement and air infiltration in a four-sided atrium office building," International Journal of Ventilation, vol. 1, no. 1, pp. 13-22, 2002.

[8] R. M. Almeida, E. Barreira, and P. Moreira, "Assessing the variability of the air change rate through tracer gas measurements," Energy Procedia, vol. 132, pp. 831-836, 2017.

[9] R. M. Almeida, M. Pinto, P. G. Pinho, and L. T. de Lemos, "Natural ventilation and indoor air quality in educational buildings: experimental assessment and improvement strategies," Energy Efficiency, vol. 10, no. 4, pp. 839-854, 2017.

[10] W. Chan, S. Cohn, M. Sidheswaran, D. Sullivan, and W. Fisk, "Contaminant levels, source strengths, and ventilation rates in California retail stores," Indoor air, vol. 25, no. 4, pp. 381392, 2015.

[11] S. Cui, M. Cohen, P. Stabat, and D. Marchio, "CO2 tracer gas concentration decay method for measuring air change rate," Building and environment, vol. 84, pp. 162-169, 2015.

[12] N. Edouard, J. Mosquera, H. J. van Dooren, L. B. Mendes, and N. W. Ogink, "Comparison of CO2-and SF6-based tracer gas methods for the estimation of ventilation rates in a naturally ventilated dairy barn," biosystems engineering, vol. 149, pp. 11-23, 2016.

[13] S. Li, J. Joe, J. Hu, and P. Karava, "System identification and model-predictive control of office buildings with integrated photovoltaicthermal collectors, radiant floor heating and active thermal storage," Solar energy, vol. 113, pp. 139-157, 2015.

[14] B. Raji, M. J. Tenpierik, and A. van den Dobbelsteen, "An assessment of energy-saving solutions for the envelope design of high-rise buildings in temperate climates: A case study in the Netherlands," Energy and Buildings, vol. 124, pp. 210-221, 2016.

[15] R.-J. Huang et al., "High secondary aerosol contribution to particulate pollution during haze events in China," Nature, vol. 514, no. 7521, p. 218, 2014.

[16] J. Gao et al., "The variation of chemical characteristics of PM2. 5 and PM10 and formation causes during two haze pollution events in urban Beijing, China," Atmospheric Environment, vol. 107, pp. 1-8, 2015.

[17] "Annual Report on China Building Energy Efficiency," Building Energy Research Center, Tsinghua University, 2017.

[18] T. L. Thatcher and D. W. Layton, "Deposition, resuspension, and penetration of particles within a residence," Atmospheric Environment, vol. 29, no. 13, pp. 1487-1497, 1995.

[19] Test method for performance of portable household electric room air cleaners, 2006.

[20] C. Monn et al., "Particulate matter less than 10 $\mu \mathrm{m}$ (PM10) and fine particles less than $2.5 \mu \mathrm{m}$ (PM2. 5): relationships between indoor, outdoor and personal concentrations," Science of the Total Environment, vol. 208, no. 1-2, pp. 15-21, 1997.

[21] L. Wallace, "Indoor particles: a review," Journal of the Air \& Waste Management Association, vol. 46, no. 2, pp. 98-126, 1996.

[22] H. Ozkaynak, J. Xue, J. Spengler, L. Wallace, E. Pellizzari, and P. Jenkins, "Personal exposure to airborne particles and metals: results from the Particle TEAM study in Riverside, California," Journal of Exposure Analysis and Environmental Epidemiology, vol. 6, no. 1, pp. 57-78, 1996.

[23] Z. Jingkun, "Analysis of causes and hazards of China's frequent hazy weather," The Open Cybernetics \& Systemics Journal, vol. 9, no. 1, 2015. 


\section{RESPONSE TO COMMENTS}

\section{REVIEWER 1'S COMMENTS:}

1. Authors names missing

Response: Authors names have been added.

2. After each chapter name the paragraph should be left indented

Response: Thanks for your comment. But the paragraph has been left indented after each chapter name.

3. Equation 1 - $P$ is the penetration factor $(0<P<1)$ ? Explain what values may $P$ take!

Response: Penetration factor indicates that some particles may deposit on the cracks of windows or doors. It is the ratio between particle concentration after penetrating and outdoor particle concentration. The value of penetration factor is between 0 and 1 . According to previous studies, between the diameter range of $0.3-10 \mu \mathrm{m}$, larger particles are easier to be deposited on the cracks and more difficult to penetrate. But for PM2.5, penetration factor is very close to 1 and usually set to 1 .

More explanations have been added in Section 2.1.

4. During the experiment the outdoor concentration seems to have diminished from $48 \mathrm{mg} / \mathrm{m} 3$ to about $43 \mathrm{mg} / \mathrm{m} 3$. Explain the way you took this into consideration.

Response: Thanks for your comment. First, it is normal for outdoor concentration to slightly fluctuate. Second, the fluctuation can be due to the accuracy of PM2.5 sensors. Third, in Fig. 3, the average outdoor concentration from $10: 00$ to $10: 30$ is $46.5 \mu \mathrm{g} / \mathrm{m}^{3}$, from 10:30 to $11: 00$ is $44.5 \mu \mathrm{g} / \mathrm{m}^{3}$, after 11:00 is $43.8 \mu \mathrm{g} / \mathrm{m}^{3}$. The fluctuation is very slight, which is within $5 \%$. 